running head: ATTACHMENT, RF, WELL-BEING IN PSYCHOTHERAPISTS

\title{
Self-Reported Reflective Functioning Mediates the Association Between Attachment Insecurity and Well-Being Among Psychotherapists
}

Agostino Brugnera $^{\mathrm{a}}$, Ph.D., Cristina Zarbo ${ }^{\mathrm{a}, \mathrm{b}}$, Ph.D., Angelo Compare ${ }^{\mathrm{a}}$, Ph.D., Alessandro Talia $^{\mathrm{c}}$, Ph.D., Giorgio A. Tasca ${ }^{\mathrm{d}}$, Ph.D., Kim de Jong ${ }^{\mathrm{e}}$, Ph.D., Andrea Greco ${ }^{\mathrm{a}}$, Ph.D., Francesco Greco $^{\mathrm{f}}$, MA, Luca Pievani ${ }^{\mathrm{g}}$, MA, Adalberto Auteri ${ }^{\mathrm{a}}$, BA, Gianluca Lo Coco ${ }^{\mathrm{h}}$, Ph.D

${ }^{a}$ Department of Human and Social Sciences, University of Bergamo, Bergamo, Italy

${ }^{\mathrm{b}}$ Unit of Epidemiological and Evaluation Psychiatry, IRCCS Istituto Centro San Giovanni di Dio Fatebenefratelli, Brescia, Italy

${ }^{\mathrm{c}}$ Institute for Psychosocial Prevention, Heidelberg University Hospital, University of Heidelberg, Heidelberg, Germany

${ }^{\mathrm{d}}$ School of Psychology, University of Ottawa, Ottawa, Canada

${ }^{\mathrm{e}}$ Institute of Psychology, Leiden University, Leiden, Netherlands

${ }^{\mathrm{f}}$ Private Practice, Bologna, Italy

${ }^{g}$ Scuola di Psicoterapia Integrata, Bergamo, Italy

${ }^{\mathrm{h}}$ Department of Psychology, Educational Sciences and Human Movement, University of Palermo, Palermo, Italy

\section{Corresponding Author:}

Agostino Brugnera, Department of Human and Social Sciences, University of Bergamo, Italy

P.le S. Agostino, 2 - 24129 Bergamo

Email: agostino.brugnera@unibg.it; Phone: +39 3402231353; ORCID: 0000-0002-40664552 
running head: ATTACHMENT, RF, WELL-BEING IN PSYCHOTHERAPISTS

Running title: Attachment, RF, Well-being in Psychotherapists

Keywords: attachment anxiety, attachment avoidance, well-being, reflective functioning, psychotherapists

Funding details: nothing to declare.

Disclosure statement: nothing to declare. 


\begin{abstract}
Objective: Subjective well-being is a crucial variable for mental health practitioners. This study examines the influence of therapists' attachment dimensions and self-reported reflective functioning on their perceived well-being. Further, it examines if reflective functioning mediates the association between attachment insecurity and well-being. Method: A total of 416 experienced psychotherapists were enrolled in this cross-sectional study, and completed self-report measures of attachment insecurity, reflective functioning, and wellbeing. We tested the hypothesized mediation model with path analysis that examined indirect effects. Results: Both attachment anxiety and avoidance dimensions had a significant negative association with perceived well-being with small to medium effects. 'Certainty' in reflective functioning had a small positive effect on therapist well-being. Reflective functioning mediated the association between insecure attachment dimensions and wellbeing, suggesting that therapist's lower ability to mentalize may partially account for the effects of higher attachment insecurity on lower well-being. Conclusion: The well-being of psychotherapists with greater insecure attachment may deserve special attention, and therapists' mentalizing capacities may be targeted by researchers and trainers as a core ability to be cultivated in order to preserve therapists' professional and personal resources.
\end{abstract}

Keywords: attachment anxiety, attachment avoidance, mentalizing, therapists, therapist factors, therapist subjective variables 


\section{Self-Reported Reflective Functioning Mediates the Association Between Attachment Insecurity and Well-Being Among Psychotherapists}

There is a growing interest among psychotherapy researchers in the influence of psychotherapists' personal well-being on their work with clients. Subjective well-being, defined as the subjective feeling of "contentment, satisfaction, or happiness derived from optimal functioning" (McDowell, 2010, p. 70) or as one's capacity for personal growth, selfactualization, and fulfilment of one's own potential and true nature (McDowell, 2010), is a crucial variable for a healthier and more functional life. A higher well-being is linked to an enhanced coping with stress, better social relationships and work-related outcomes, at least among the general population (McDowell, 2010; Steptoe, Deaton, \& Stone, 2015; Zelenski, Murphy, \& Jenkins, 2008).

A focus on psychotherapists' well-being is consistent with the recent emphasis in psychotherapy research on a broad range of therapist personal variables that may influence the quality of the therapeutic relationship (for a review, see Cuijpers, Reijnders, \& Huibers, 2019; Heinonen \& Nissen-Lie, 2019; Kraus, Castonguay, Boswell, Nordberg, \& Hayes, 2011; Lingiardi, Muzi, Tanzilli, \& Carone, 2018; Steel, Macdonald, \& Schroder, 2018).

Therapeutic work can be an emotionally demanding experience for therapists and can impact on their levels of subjective well-being. Therapists often engage in close professional relationships with their patients. Therapists listen carefully and provide empathy, deal with a range of intense emotions in patients, manage their own thoughts, behaviors and feelings, and sometimes manage intense interpersonal dynamics that emerge in the therapy (Kraus et al., 2011; Puig, Yoon, Callueng, An, \& Lee, 2014). However, little is known about the therapists' characteristics that can foster a greater well-being among psychotherapists. The current study aims to examine how two key therapist characteristics, namely attachment insecurity and 
mentalizing capacity, can affect well-being in a large sample of experienced psychotherapists. Both attachment and mentalizing are central to the therapy process such that they may enhance therapists' effectiveness in working with strong emotions and countertransference (Heinonen \& Nissen-Lie, 2019; Lingiardi et al., 2018), and so it is worth examining their influence on therapists' well-being.

\section{Well-being, attachment and reflective functioning}

Several notable studies have examined the link between therapists' well-being and their quality of life and professional functioning. In a book that has now become a classic, Henry, Sims and Spray (1973) discussed how therapists tend to merge the personal and professional dimensions of their life. Guy, Poelstra, and Stark (1989) showed that, in a sample of 318 therapists, $74.3 \%$ experienced personal distress in the previous three years, and $36.7 \%$ of those believed that it negatively affected their work. In their review of therapists' personal variables, Beutler and colleagues (2004) reported that clinicians' sense of selfefficacy was related to their perceived well-being. Orlinsky and Rønnestad (2005) in a largescale study of therapists in training highlighted a significant association between therapists' personal burdens and stressful engagement in therapy. More recently, research found that therapists who reported a satisfying private life tended to rate higher therapeutic alliances with their patients (Delgadillo, Saxon, \& Barkham, 2018; Heinonen \& Nissen-Lie, 2019; Nissen-Lie, Havik, Hoglend, Monsen, \& Ronnestad, 2013).

Previous research has also examined some individual variables associated with therapists' well-being. For example, Linley and Joseph (2007) found that therapists who were in personal therapy, who received clinical supervision, with less clinical experience, and who had higher levels of coherence and empathy reported greater well-being. Richards, Campenni, and Muse-Burke (2010) showed that specific personality traits like self-awareness 
and mindfulness were positively related to personal well-being of mental health professionals, and that engaging in proactive self-care strategies decreased the possibility of impairment and increased clinicians' quality of life. Taken together, these studies suggest that lower well-being can have a negative impact on a therapist's work, and it is likely that this influence may depend on how clinicians manage problems in their personal lives.

Consistently, the investigation of therapists' own psychological resources can shed some light on their subjective well-being.

To date, there is evidence from the general population that two relevant predictors of subjective well-being are attachment insecurity (i.e., avoidant and anxious dimensions) and mentalizing capacity (Mikulincer \& Shaver, 2016). However, the role of these variables as predictors of well-being among psychotherapists is still under-investigated. According to the attachment theory (Bowlby, 1969), the quality of early interactions with caregivers leads to development of secure or insecure attachment that in turn may be characterized by two main dimensions, namely attachment avoidance and attachment anxiety (Brennan, Clark, \& Shaver, 1998; Tasca et al., 2018). Individuals with higher attachment avoidance tend to establish and maintain independence, control and autonomy, as well as deactivate emotions and limit emotional experiences during their life and in romantic relationships (Cassidy \& Kobak, 1988; Mikulincer \& Shaver, 2016; Simpson \& Rholes, 2018). Conversely, individuals with higher attachment anxiety show difficulties in regulating their negative emotions and in trusting others, and with recurrent feeling or fear of being abandoned in intimate relationships (Mikulincer, 1995; Mikulincer \& Shaver, 2016). There is evidence that the ability to build positive and fulfilling personal relationships with significant others (i.e., attachment security) can contribute to happiness and quality of life (Karreman \& Vingerhoets, 2012; Wei, Liao, Ku, \& Shaffer, 2011). In samples of college students and community adults, higher secure attachment was positively related to higher well-being, 
while higher anxious and avoidant attachment were negatively associated with well-being (e.g., Kafetsios \& Sideridis, 2006; Karreman \& Vingerhoets, 2012; La Guardia, Ryan, Couchman, \& Deci, 2000; Li \& Zheng, 2014; Mikulincer \& Shaver, 2016; Wei et al., 2011).

In psychotherapy research, most of the previous studies examined the impact of therapists' attachment dimensions on the quality of therapeutic relationship (Strauss \& Petrowski, 2017). However, there is a dearth of research investigating the influence of therapists' attachment dimensions on therapists' own well-being. According to attachment theory, there are at least three aspects of adult attachment that may contribute to lower selfreported well-being, including: (a) adopting dysfunctional emotion regulation strategies in the face of stressors, (b) having negative representations of oneself and thus lower self-esteem, and (c) facing chronic interpersonal problems (Mikulincer \& Shaver, 2012).

Mentalizing capacity is also associated with greater well-being during the entire lifespan (Borelli et al., 2018; Fonagy, Gergely, Jurist, \& Target, 2002; Fonagy et al., 2016). Mentalizing, or reflective functioning (RF), refers to the capacity to understand and interpret -implicitly and explicitly- one's own and others' behaviour as an expression of specific feelings, desires, thoughts, attitudes, or goals (Fonagy, Bateman, \& Bateman, 2011; Fonagy, Steele, Steele, Moran, \& Higgitt, 1991; Fonagy \& Target, 2002; Fonagy, Target, Steele, \& Steele, 1998; Katznelson, 2014; Luyten \& Fonagy, 2015; Steele, Steele, Croft, \& Fonagy, 1999). Considered a multidimensional construct, mentalizing seems to be captured well by the dimensions of "certainty" and "uncertainty" regarding one's own and others' mental states (i.e., feelings, desires, thoughts, attitudes, or goals; Fonagy et al., 1998). The capacity to mentalize develops in the context of secure attachment relationships as the result of a child's experience of being held in mind by a secure attachment figure, and of the child having their intentions and feelings reflected back to them by the attachment figure (Fonagy \& Target, 1997). Conversely, insecure attachment relationships - in interaction with genetic 
and environmental vulnerabilities- have been associated with impairments in mentalizing (Fonagy \& Target, 1997; Luyten \& Fonagy, 2015). It follows that individuals with insecure attachment usually report lower mentalizing capacities (see for example Hayden, Müllauer, Gaugeler, Senft, \& Andreas, 2019).

Individuals with good reflective functioning can hold in mind multiple concurrent points of view, are aware of their own mental states, are able to tease out mental states that underlie behaviors, and are aware of the opaque nature of their own and others' mental states (Fonagy et al., 2016). Due to its specific characteristics, reflective functioning is often considered as a mediator in the association between insecure adult attachment and psychological distress or personality factors (see for example Badoud et al., 2017; Hayden et al., 2019; Nazzaro et al., 2017). That is, because mentalizing allows individuals to perceive, label, and consider emotions as the basis of behaviors (Fonagy et al., 2002), it is associated with important psychological abilities, including distress tolerance, interpersonal skills, and emotion regulation (Morel \& Papouchis, 2015; Schultheis, Mayes, \& Rutherford, 2019). These associations may explain how and why higher reflective functioning may contribute to greater well-being (Borelli et al., 2018).

To date, the empirical evidence suggests that therapists' attachment and reflective functioning affect the quality of their work, and may contribute to their ability to enter into an empathic and responsive relationship with their clients (Cologon et al., 2017; Lingiardi et al., 2018; Steel et al., 2018). However, little is known about the link between reflective functioning, attachment dimensions and therapists' well-being. The current study aims to fill this gap in the literature on therapists' characteristics.

\section{The present study}


The main purpose of the current study is to test the direct influence of attachment insecurity (i.e., anxiety and avoidance dimensions) and self-reported reflective functioning on well-being in a large sample of psychotherapists, as well as to test if reflective functioning mediates the relationship between attachment insecurity and well-being. We see this study as especially relevant because attachment and reflective functioning are widely-investigated variables among therapists, and both are central to the therapy process such that they may enhance therapists' effectiveness in working with strong emotions and countertransference in therapy (Cologon et al., 2017; Ensink et al., 2013; Heinonen \& Nissen-Lie, 2019; Lingiardi et al., 2018; Mikulincer \& Shaver, 2016). We tested three main hypotheses related to the complex association between attachment, reflective functioning and well-being. Based on the literature reviewed above, we hypothesized that: (1) therapists' attachment anxiety and avoidance will be negatively related to both their reflective functioning and their well-being, (2) therapists' reflective functioning will be positively related to their well-being, and (3) higher reflective functioning in therapists will mediate the association between insecure attachment dimensions (anxiety and avoidance) and well-being.

\section{Method}

\section{Participants}

We enrolled a total of 416 psychotherapists (females: $79.6 \%$; mean age: $43.94 \pm 10.37$ years) in this study. All participants were white and of Italian ethnicity; $76 \%$ were in a relationship, $17.5 \%$ was single and $6.5 \%$ was divorced/widowed. All participants had at least a master's degree in Psychology and had attended a four-to-five year specialization in a psychotherapy training institution. In addition, $8.4 \%$ of the participants had a Ph.D. in a related field. In our study, $65.7 \%$ of the entire sample followed an integrative approach, $13.6 \%$ a psychodynamic approach, and $11.6 \%$ a cognitive-behavioral approach. The participants practiced psychotherapy for a mean of $10.1 \pm 9.23$ years. 


\section{Measures}

Attachment. The Italian version of the Experiences in Close Relationships - Revised (ECR-R; Busonera, Martini, Zavattini, \& Santona, 2014; Fraley, Waller, \& Brennan, 2000) is a 36-item self-report measure of attachment to romantic partners. The ECR-R was developed following an Item Response Theory analysis of different attachment items (drawn from 4 self-report inventories of attachment) that were administered to a large sample of university students during the validation of the original ECR questionnaire (Brennan et al., 1998). The ECR-R measures two dimensions of attachment to romantic partners, namely attachment avoidance (18 items; e.g., "I prefer not to show a partner how I feel deep down") and attachment anxiety (18 items; e.g. "I often worry that my romantic partner doesn't really love $m e$ "). Items are scored on a 7-point Likert scale ( $1=$ strongly disagree; $7=$ strongly agree $)$. Mean total scores range from 1 to 7 , with higher scores indicating greater attachment avoidance or attachment anxiety with romantic partners. The Italian version of this measure was obtained through a back- and forward-translation procedure and validated in a sample of adults. The ECR-R has good psychometric properties (Busonera et al., 2014; Fraley et al., 2000). Regarding the construct validity, the ECR-R scales correlate positively with other selfreport measures of Attachment and of psychological distress, and negatively with measures of dyadic adjustment (Busonera et al., 2014). Test-retest reliability (assessed after 100 days) is also satisfactory, with an ICC $>.70$ for both subscales (Busonera et al., 2014). In the current study, Cronbach alphas of both subscales were good to excellent (.89 for Attachment Anxiety and .91 for Attachment Avoidance).

Self-reported Reflective Functioning. The Italian version of the Reflective Functioning Questionnaire (RFQ; Fonagy et al., 2016; Morandotti et al., 2018) is an 8-item self-report measure of reflective functioning, or mentalizing. It measures two different domains: Certainty about mental states (RFQ C; e.g., "People's thoughts are a mystery to 
me”) and Uncertainty about mental states (RFQ U; e.g., "When I get angry I say things without really knowing why I am saying them"). In the RFQ, items are initially scored on a 7point Likert-type scale $(1=$ strongly disagree; 7 = strongly agree $)$. Items are subsequently rescored to capture more extreme levels of certainty and uncertainty about mental states. As regards RFQ C, items are recoded to 3,2,1,0,0,0,0, and "higher scores on this scale reflect the acknowledgement of mental states' opaqueness and therefore a more genuine level of mentalizing" (Sacchetti et al., 2019). As regards RFQ U, items are recoded to 0, 0, 0, 0, 1, 2, 3, so that lower scores on this scale reflect a more genuine mentalizing (i.e., acknowledgment of the opaqueness of mental states, or the ability to consider complex models of one's own mind and/or those of others). Total scores for each subscale range from 0 to 18 .

The Italian version of the RFQ was obtained through a back- and forward-translation procedure (Morandotti et al., 2018). Research indicated that the RFQ has good internal, convergent and divergent validity, as well as a good reliability (Fonagy et al., 2016; Morandotti et al., 2018). Regarding the construct validity, the RFQ scales correlate in opposite directions with measures of perspective-taking, psychological distress, empathy and mindfulness, and with both self-reported and clinician-rated measures of maladaptive personality functioning (Fonagy et al., 2016; Morandotti et al., 2018; Sacchetti et al., 2019). The RFQ scales also discriminate well between patients with personality or eating disorders and healthy controls, with patients scoring higher on the RFQ U and significantly lower on the RFQ C than controls (Morandotti et al., 2018; Sacchetti et al., 2019). In addition, a mediation model tested by Fonagy and colleagues (2016) showed that the RFQ C scale scores of mothers are indirectly associated with the secure attachment status of their infants (examined through the Strange Situation procedure), and this is explained by the negative association of RFQ C with the maladaptive attributions concerning one's child. Finally, the 
test-retest reliability of the RFQ after an interval of two weeks is also good, with ICCs $>.80$ for both subscales (Morandotti et al., 2018).

In the current study, Cronbach's alphas for both subscales were low to acceptable (.64 for RFQ U, .72 for RFQ C), while inter-item correlations ranged from .23 (RFQ U) to .30 (RFQ C). Inter-item correlation coefficients in the range of .15-.50 indicate good internal consistency of a scale (Clark \& Watson, 1995).

Well-being. The Italian version of the Psychosocial General Well-Being Index (PGWBI; Dupuy, 1984; Grossi, Mosconi, Groth, Niero, \& Apolone, 2002) is a 22-item selfreport questionnaire that evaluates psychological and general quality of life during a 4-week period. Considered one the most psychometrically-sound measures of self-perceived wellbeing (McDowell, 2010), the PGWBI measures six health-related quality of life domains, namely anxiety, depressed mood, positive well-being, self-control, general health and vitality. Each item was rated on a 6-point Likert scale ( 0 to 5). Total scores range from 0 to 110 , with higher scores indicating greater well-being. An example of item is "Ifelt cheerful, lighthearted during the past month". The Italian version of this measure was obtained through a back- and forward-translation procedure, and has good psychometric properties (Grossi et al., 2002; Lundgren-Nilsson, Jonsdottir, Ahlborg, \& Tennant, 2013). Regarding the construct validity, the PGWBI correlates well with other measures of psychological distress and positive affect (Dupuy, 1984; Grossi \& Compare, 2014). The test-retest reliability across different studies is also good, with a median ICC of .80 (Grossi \& Compare, 2014). In the present study, the Cronbach's alpha for the total score was excellent (.92).

\section{Procedure}

Cross-sectional data were collected online from a sample of Italian psychotherapists from October 2016 to August 2018. To achieve a large sample, we adopted four recruitment 
strategies. First, we contacted several psychotherapy training institutions asking them to collaborate with the study by emailing the survey link to former clinical students. Second, we placed notices on social media groups for therapists inviting clinicians to complete a battery of questionnaires and providing a link to the online survey. Third, during several clinical conferences \congresses held in Italy, two authors (GLC and AC) presented the research and asked the audience to complete the survey. Fourth, we sent emails to selected professional contacts in the mental health field, inviting recipients to complete the survey and to forward the invitation to any colleagues or networks that they thought might be interested in participating to the study. To ensure that no individuals completed the battery more than once, we initially collected personal information (e.g., IP addresses) which was anonymized once data gathering was completed.

This study was conducted in accordance with ethical standards for the treatment of human experimental volunteers. Those who agreed to participate (i.e., provided informed consent) were subsequently redirected to a webpage detailing the overall aims of the research and the names and contact information of the researchers; Participants then had access to a demographic survey and a battery of questionnaires. The latter were completed in the following order: first the ECR-R, then the RFQ and finally the PGWBI. Inclusion criteria were: (1) completed a post-graduate program in a psychotherapy training institution, or a medical school degree with post-graduate specialization in psychiatry; and (2) being an Italian native speaker.

\section{Statistical Analysis}

We tested the hypothesized mediation model using a path analysis with observed variables. Parameter estimates were computed using a maximum likelihood estimation method, while an optimal model fit was evaluated using the following criteria: a normed chisquared of 3 or less, a root mean square error of approximation (RMSEA) of 0.05 or less, an 
upper RMSEA's $90 \%$ confidence interval bound of 0.08 or less, a comparative fit index (CFI) and a Tucker-Lewis index (TLI) of 0.95 or more, and a standardized root mean squared residual (SRMR) of 0.05 or less (Hu \& Bentler, 1999). The magnitude of path coefficients was interpreted according to Cohen's criteria $($ small $=0.1 ;$ medium $=0.3 ;$ large $=0.5$; Cohen, 1988).

We initially tested the relationship between attachment avoidance, attachment anxiety and well-being, and then the relationship between reflective functioning and well-being. As a second step we examined the mediating role of reflective functioning between the attachment scales and well-being, controlling for the effects of age and gender (see Figure 1). We computed indirect (i.e., mediated) effects and their standard errors using a bootstrap procedure, saving parameter estimates drawn from 5000 bootstrap samples. As suggested by Byrne (2016), if the 95\% confidence intervals (CI) of these estimates do not include zero, then the indirect effect is statistically significant at the .05 level. We reported the proportion mediated (PM: the ratio of the indirect effect to the total effect; Preacher \& Kelley, 2011) as effect size of indirect effects. Other effect sizes (i.e., Pearson $r$ correlation indexes) were interpreted according to guidelines (Cohen, 1988). We performed analyses using Analysis of Moment Structures (AMOS) and Statistical Package for Social Sciences (SPSS) version 25.0. All statistical tests were two-tailed, and a $p$ value $\leq .05$ was considered statistically significant. All the resulting $p$-values were further corrected with the Benjamini-Hochberg procedure for false discovery rate (Benjamini \& Hochberg, 1995).

\section{Results}

\section{Preliminary Analyses}

We evaluated the presence of multivariate outliers and identified a total of twelve cases that were removed from subsequent analyses (Tabachnick \& Fidell, 2007). No univariate outliers were identified. However, RFQ U was strongly positively skewed, the 
ECR-R Attachment Anxiety and Attachment Avoidance subscales were moderately positively skewed, and the PGWBI total score was slightly negatively skewed. Thus, we corrected the non-normality in these scales with a reflect and inverse transformation, a $\log 10$ transformation, and a reflect square-root transformation, respectively. Finally, age was significantly related with PGWBI Total score (see Table 1).

Means, standard deviations, and zero-order correlations for all psychological variables are also reported in Table 1.

\section{Main Analyses}

The mediation model was a very good fit to the data: normed $\chi^{2}(8)=1.046, p=.43$; RMSEA $=0.011,90 \%$ CIs $(.01, .06) ; \mathrm{CFI}=.99 ; \mathrm{TLI}=.99 ; \mathrm{SRMR}=.02$. As shown in Figure 1 (which reports standardized direct effects), age had a small but significant effect on the PGWBI total score, suggesting that older clinicians experience a higher perceived well-being. The results supported the first hypothesis that therapists' attachment insecurity will be negatively related to both their reflective functioning and well-being. Attachment anxiety and avoidance were significantly and negatively associated with certainty about mental states (RFQ-C; with medium and small effects, respectively), positively associated with uncertainty about mental states, and negatively associated with well-being (with small effects). Of note, the effect of attachment anxiety on certainty in reflective functioning was significantly larger than the effect of attachment avoidance on certainty in reflective functioning $\left(\Delta \chi^{2}=9.703\right.$; $D F=1 ; p=.002)$. The results partially supported hypothesis two that a higher reflective functioning will be positively related to well-being. Certainty about mental states was significantly and positively associated with therapist well-being (with small effects). However, uncertainty about mental states was not associated with PGWBI (see Figure 1). All aforementioned paths were significant even after controlling simultaneously for all other variables and paths within the model. 
The results supported hypothesis three that reflective functioning will mediate the association between attachment insecurity and well-being. The two RF subscales were significant, partial mediators of attachment insecurity on well-being. There was a significant indirect effect of both attachment insecurity dimensions on well-being through RF (standardized indirect effect for Attachment Anxiety: -.11, $p<.001$, bias corrected CIs [$.068,-.160], \mathrm{P}_{\mathrm{M}}=31 \%$; standardized indirect effect for Attachment Avoidance: -.05, $p=$ .003 ; bias corrected CIs [-.016, -.082]; $\mathrm{P}_{\mathrm{M}}=19.8 \%$ ). That is, for each unit increase in Attachment Anxiety there was a decrease of 0.11 standard deviations in PGWBI through a sequence of steps in which Attachment Anxiety reduces certainty about mental states and increases uncertainty about mental states (i.e., its effect on the mediators), which in turn negatively affects well-being. The tested model explained the $34 \%$ of the variance in wellbeing (i.e., the PGWBI outcome variable).

\section{Discussion}

Although there is mounting research on the personal characteristics of therapists, there is still a lack of empirical investigation on therapist's subjective well-being. This study was the first to examine the association between attachment anxiety and avoidance, self-reported reflective functioning and well-being in a large sample of experienced psychotherapists of different therapy orientations. We found support for our first set of hypotheses such that attachment anxiety and attachment avoidance were negatively related to therapist well-being, and certainty in reflective functioning was positively related to well-being. We also found support for our third hypothesis such that the effect of higher attachment anxiety and avoidance on well-being was mediated or explained partially by reflective functioning. These results suggest that insecure attachment can adversely affect therapists' well-being, and that these associations are in part due to the effects of attachment insecurity on reducing reflective functioning. 
Results related to our first hypothesis indicated that higher therapists' insecure attachment dimensions (anxiety and avoidance) predicted lower well-being is in line with past studies on clinical and non-clinical populations (e.g., Kafetsios \& Sideridis, 2006; Karreman \& Vingerhoets, 2012; La Guardia et al., 2000; Li \& Zheng, 2014; Mikulincer \& Shaver, 2016; Wei et al., 2011). We also found that the two attachment-related dimensions had significant direct effects on certainty and uncertainty about mental states. Interestingly, attachment anxiety had larger effects on certainty in reflective functioning than attachment avoidance. One explanation for this result might be that therapists with greater attachment avoidance adopt specific emotion regulation strategies related to minimizing emotional experiences that prevent them from being aware of negative emotional states. For example, higher attachment avoidance among therapists might lead to disengaging their attention from distressing experiences and mental states, thus leading to somewhat higher RF at least relative to anxiously-attached therapists.

The results related to our second hypothesis replicated the finding from studies of community samples that certainty in reflective functioning has a direct and significant effect on well-being (Borelli et al., 2018; Fonagy et al., 2002; Fonagy et al., 2016). However, we did not find that uncertainty in reflective functioning was associated with well-being. This finding may be due to the characteristics of our sample, which was composed by clinicians who underwent extensive training to provide psychotherapy. Compared to the average scores of the general population (Fonagy et al., 2016), the therapists in our sample reported very low levels of uncertainty about mental states (i.e., the variable was positively skewed).

Findings in support of our third hypothesis suggest that the therapist's ability to mentalize may partially account for the effects of higher attachment insecurity on lower wellbeing. Consistent with previous studies, we found that greater attachment insecurity was associated with lower reflective functioning (e.g., Hayden et al., 2019). In addition to that, 
lower reflective functioning in itself suggests a reduced capacity to engage and empathize with others, and to hold others in mind. In the context of attachment insecurity, a lower mentalizing capacity could both make a therapist more susceptible to stressful experiences and lead to a worse emotion regulation, thus reducing the subjective well-being. On the other hand, higher levels of reflective functioning may serve as a protective factor when it comes to well-being. In a tangential study on 25 therapists, Cologon and colleagues (2017) found that higher reflective functioning compensated for insecure attachment in therapists in terms of patient outcomes. Similarly, Mallinckrodt (2000) suggested that therapists' attachment dimensions can be less important than the way these dimensions facilitate emotion regulation and responsiveness in therapy relationship. Previous research found a weak direct effect of therapist attachment on patient outcomes (Bucci, Seymour-Hyde, Harris, \& Berry, 2016; Heinonen \& Nissen-Lie, 2019; Lingiardi et al., 2018), suggesting that attachment styles may affect psychotherapeutic processes indirectly through other variables. Our study adds to the literature suggesting that higher levels of reflective functioning could make therapists with greater attachment insecurity better able to tolerate distress and to regulate their emotions, leading to a higher well-being. Further research is necessary to investigate the interplay between therapists' attachment, mentalization, and well-being, as well as to examine if a higher well-being make therapists less susceptible to the difficulties of clinical work and has direct effects on patient outcomes.

We also found that age had a small but significant association with well-being, suggesting that older therapists reported a higher well-being. These findings are similar to those reported in the general population (Steptoe et al., 2015). Although less physically healthy and less productive in general, older adults may be more satisfied with their lives and to experience less negative affect compared to younger individuals. At the same time, compared to younger therapists, older psychotherapists typically experience better 
psychosocial and economic conditions, and have more realistic expectations towards life in terms of adaptation to their life circumstances and career goals (Ulloa, Møller, \& Sousa-Poza, 2013).

There are some important limitations to our study. First, the data were cross-sectional in nature which prevents us from drawing conclusions regarding causality. Mediation analyses of cross-sectional data should be interpreted with special caution, given that different models are mathematically equivalent to the main one tested in this study and could provide similar fits to the data (Fiedler, Schott, \& Meiser, 2011). Future research testing a mediation model of attachment, mentalizing, and well-being should be carried out within a longitudinal design to test the causal relationship between attachment dimensions and wellbeing explained by reflective functioning. Our exclusive focus on self-report instruments for assessing attachment and mentalizing may also lead to over-emphasizing consciously available information at the expense of more implicit aspects of attachment and mentalizing (Tasca \& Balfour, 2014). Adopting implicit measures of these constructs, such as the Adult Attachment Interview (AAI) and the Reflective Functioning Scale (which is rated starting from AAI transcripts; Fonagy et al., 1998) could provide more nuanced information, as well as testing if our findings can be replicated while controlling for shared method variance. Finally, the RFQ was developed to assess severe impairments in mentalizing as typically observed in patients with personality disorders (Fonagy et al., 2016). Thus, it may be that the non-significant effects of the Uncertainty subscale on well-being (as well as its low Cronbach's alpha) were due to the characteristics of our sample, composed exclusively of mental health practitioners who scored very low on this subscale.

Although researchers have examined the association between attachment style, reflective functioning, and the therapeutic process, this study was the first to examine their role in predicting therapists' well-being in a large sample of clinicians. Our findings point to 
the association between these constructs and the special importance of both reflective functioning and attachment insecurity for therapists' well-being. Due to work-related pressures associated with clinical activity, mental health agencies are implementing training programs and professional development modules focused on reducing the therapists' emotional exhaustion (Blow, 2017; Wise, Hersh, \& Gibson, 2012). Along this line, our study highlights the potential importance of targeting therapists' reflective functioning in the professional development and training of psychotherapists (particularly those with greater attachment insecurity), with the aim of improving their well-being and perhaps, in turn, their effectiveness in their work with clients. Personal therapy and supervision could be two ways to increase reflective functioning among therapists or trainees in psychotherapy. Mental health agencies could also provide a specific mentalization-based training program focused on boosting the emotional self-awareness, self-monitoring, and the emotional differentiation competencies of the participants. Recall that a lower reflective functioning is characterized by an impairment in discriminating between emotions (e.g., sadness from fear) which may lead to inaccurate attributions of the current mental state experienced by the individual. Mentalization based training for psychotherapists could increase reflective functioning through exercises on accurately labelling emotions, identifying the mental states in others, and on identifying the association between emotions, thoughts, and behaviours. A greater degree of understanding of one's own mental states and the mental states of clients could improve a therapist's capacity to tolerate and manage emotions common in countertransference, and could improve their capacity for empathy (Cologon et al., 2017; Ensink et al., 2013; Heinonen \& Nissen-Lie, 2019; Lingiardi et al., 2018; Mikulincer \& Shaver, 2016). As our results suggest, a greater capacity to mentalize may also promote a greater sense of well-being and so likely lead to a healthier and more satisfying life for psychotherapists. 


\section{References}

Badoud, D., Prada, P., Nicastro, R., Germond, C., Luyten, P., Perroud, N., \& Debbané, M. (2017). Attachment and Reflective Functioning in Women With Borderline Personality Disorder. Journal of Personality Disorders, 32(1), 17-30. doi:10.1521/pedi_2017_31_283

Benjamini, Y., \& Hochberg, Y. (1995). Controlling the False Discovery Rate: A Practical and Powerful Approach to Multiple Testing. Journal of the Royal Statistical Society: Series B (Methodological), 57(1), 289-300. doi:10.1111/j.2517-6161.1995.tb02031.x

Beutler, L. E., Malik, M., Alimohamed, S., Harwood, T. M., Talebi, H., Noble, S., \& Wong, E. (2004). Therapist variables. In M. J. Lambert (Ed.), Bergin and Garfield's Handbook of Psychotherapy and Behavior Change (5th ed., pp. 227-306). New York, NY: John Wiley \& Son, Inc.

Blow, A. J. (2017). The Therapist's Role in Effective Therapy: Three Key Priorities for Research. Administration and Policy in Mental Health and Mental Health Services Research, 44(5), 729-731. doi:10.1007/s10488-017-0804-3

Borelli, J. L., Brugnera, A., Zarbo, C., Rabboni, M., Bondi, E., Tasca, G. A., \& Compare, A. (2018). Attachment comes of age: adolescents' narrative coherence and reflective functioning predict well-being in emerging adulthood. Attachment \& Human Development, 1-20. doi:10.1080/14616734.2018.1479870

Bowlby, J. (1969). Attachment and loss: Vol. 1. Attachment. New York, NY: Basic Books.

Brennan, K. A., Clark, C. L., \& Shaver, P. R. (1998). Self-report measurement of adult attachment: An integrative overview. In J. A. Simpson \& W. S. Rholes (Eds.), Attachment theory and close relationships (pp. 46-76). New York, NY: Guilford Press.

Bucci, S., Seymour-Hyde, A., Harris, A., \& Berry, K. (2016). Client and Therapist Attachment Styles and Working Alliance. Clinical Psychology \& Psychotherapy, 23(2), 155-165. doi:10.1002/cpp.1944 
Busonera, A., Martini, P. S., Zavattini, G. C., \& Santona, A. (2014). Psychometric properties of an Italian version of the Experiences in Close Relationships-Revised (ECR-R) Scale. Psychological Reports, 114(3), 785-801. doi:10.2466/03.21.PR0.114k23w9

Byrne, B. M. (2016). Structural equation modeling with AMOS: Basic concepts, applications, and programming. Mahwah, NJ: Lawrence Erlbaum Associates.

Cassidy, J., \& Kobak, R. R. (1988). Avoidance and its relation to other defensive processes. In J. Belsky (Ed.), Clinical implications of attachment (Vol. 1, pp. 300-323). Mahwah, NJ: Lawrence Erlbaum Associates.

Clark, L. A., \& Watson, D. (1995). Constructing validity: Basic issues in objective scale development. Psychological Assessment, 7(3), 309-319. doi:10.1037/1040-3590.7.3.309

Cohen, J. (1988). Statistical Power Analysis for the Behavioral Sciences (2nd ed.). Hillsdale, NJ: Erlbaum.

Cologon, J., Schweitzer, R. D., King, R., Nolte, T. J. A., Health, P. i. M., \& Research, M. H. S. (2017). Therapist Reflective Functioning, Therapist Attachment Style and Therapist Effectiveness. Administration and Policy in Mental Health and Mental Health Services Research, 44(5), 614-625. doi:10.1007/s10488-017-0790-5

Cuijpers, P., Reijnders, M., \& Huibers, M. J. H. (2019). The Role of Common Factors in Psychotherapy Outcomes. Annual Review of Clinical Psychology, 15(1). doi:10.1146/annurev-clinpsy-050718-095424

Delgadillo, J., Saxon, D., \& Barkham, M. (2018). Associations between therapists' occupational burnout and their patients' depression and anxiety treatment outcomes. Depression \& Anxiety, 35(9), 844-850. doi:10.1002/da.22766

Dupuy, H. J. (1984). The Psychological General Wellbeing (PGWB) Index. In N. K. Wenger, M. E. Mattson, C. D. Furburg, \& J. Elinson (Eds.), Assessment of Quality of Life in Clinical Trials of Cardiovascular Therapies (pp. 170-183). New York, NY: Le Jacq Publishing. 
Ensink, K., Maheux, J., Normandin, L., Sabourin, S., Diguer, L., Berthelot, N., \& Parent, K. (2013). The impact of mentalization training on the reflective function of novice therapists: a randomized controlled trial. Psychotherapy Research, 23(5), 526-538. doi:10.1080/10503307.2013.800950

Fiedler, K., Schott, M., \& Meiser, T. (2011). What mediation analysis can (not) do. Journal of Experimental Social Psychology, 47(6), 1231-1236. doi:10.1016/j.jesp.2011.05.007

Fonagy, P., Bateman, A., \& Bateman, A. (2011). The widening scope of mentalizing: A discussion. Psychology and Psychotherapy: Theory, Research and Practice, 84(1), 98-110. doi:10.1111/j.2044-8341.2010.02005.x

Fonagy, P., Gergely, G., Jurist, E. L., \& Target, M. (2002). Affect regulation, mentalization, and the development of the self. New York, NY: Other Press.

Fonagy, P., Luyten, P., Moulton-Perkins, A., Lee, Y. W., Warren, F., Howard, S., . . Lowyck, B. (2016). Development and Validation of a Self-Report Measure of Mentalizing: The Reflective Functioning Questionnaire. PLoS One, 11(7), e0158678. doi:10.1371/journal.pone.0158678

Fonagy, P., Steele, M., Steele, H., Moran, G. S., \& Higgitt, A. C. (1991). The capacity for understanding mental states: The reflective self in parent and child and its significance for security of attachment. Infant Mental Health Journal, 12(3), 201-218. doi:10.1002/10970355(199123)12:3\%3C201::AID-IMHJ2280120307\%3E3.0.CO;2-7

Fonagy, P., \& Target, M. (1997). Attachment and reflective function: Their role in selforganization. Development and Psychopathology, 9(4), 679-700. doi:10.1017/S0954579497001399

Fonagy, P., \& Target, M. (2002). Early intervention and the development of self-regulation. Psychoanalytic Inquiry, 22(3), 307-335. doi:10.1080/07351692209348990

Fonagy, P., Target, M., Steele, H., \& Steele, M. (1998). Reflective-functioning manual, version 5.0, for application to adult attachment interviews. London: University College London. 
Fraley, C. R., Waller, N. G., \& Brennan, K. A. (2000). An item response theory analysis of selfreport measures of adult attachment. Journal of Personality and Social Psychology, 78(2), 350-365. doi:10.1037/0022-3514.78.2.350

Grossi, E., \& Compare, A. (2014). Psychological General Well-Being Index (PGWB). In A. C. Michalos (Ed.), Encyclopedia of Quality of Life and Well-Being Research (pp. 5152-5156). Dordrecht: Springer Netherlands.

Grossi, E., Mosconi, P., Groth, N., Niero, M., \& Apolone, G. (2002). Il Questionario Psychological General Well Being. Questionario per la valutazione dello stato generale di benessere psicologico. Versione Italiana. Istituto di Ricerche Farmacologiche "Mario Negri". Milan.

Guy, J. D., Poelstra, P. L., \& Stark, M. J. (1989). Personal distress and therapeutic effectiveness: National survey of psychologists practicing psychotherapy. Professional Psychology: Research and Practice, 20(1), 48-50. doi:10.1037/0735-7028.20.1.48

Hayden, M. C., Müllauer, P. K., Gaugeler, R., Senft, B., \& Andreas, S. (2019). Mentalization as Mediator between Adult Attachment and Interpersonal Distress. Psychopathology, 52(1), 10-17. doi:10.1159/000496499

Heinonen, E., \& Nissen-Lie, H. A. (2019). The professional and personal characteristics of effective psychotherapists: a systematic review. Psychotherapy Research, 1-16. doi:10.1080/10503307.2019.1620366

Henry, W. E., Sims, J. H., \& Spray, S. L. (1973). Public and private lives of psychotherapists. Oxford, England: Jossey-Bass.

Hu, L. t., \& Bentler, P. M. (1999). Cutoff criteria for fit indexes in covariance structure analysis: Conventional criteria versus new alternatives. Structural Equation Modeling: A Multidisciplinary Journal, 6(1), 1-55. doi:10.1080/10705519909540118

Kafetsios, K., \& Sideridis, G. D. (2006). Attachment, Social Support and Well-being in Young and Older Adults. Journal of Health Psychology, 11(6), 863-875. doi:10.1177/1359105306069084 
Karreman, A., \& Vingerhoets, A. J. J. M. (2012). Attachment and well-being: The mediating role of emotion regulation and resilience. Personality and Individual Differences, 53(7), 821-826. doi:10.1016/j.paid.2012.06.014

Katznelson, H. (2014). Reflective Functioning: a review. Clinical Psychology Review, 34(2), 107117. doi:10.1016/j.cpr.2013.12.003

Kraus, D. R., Castonguay, L. G., Boswell, J. F., Nordberg, S. S., \& Hayes, J. A. (2011). Therapist effectiveness: Implications for accountability and patient care. Psychotherapy Research, 21(3), 267-276. doi:10.1080/10503307.2011.563249

La Guardia, J. G., Ryan, R. M., Couchman, C. E., \& Deci, E. L. (2000). Within-person variation in security of attachment: A self-determination theory perspective on attachment, need fulfillment, and well-being. Journal of Personality and Social Psychology, 79(3), 367-384. doi:10.1037/0022-3514.79.3.367

Li, X., \& Zheng, X. (2014). Adult Attachment Orientations and Subjective Well-Being: Emotional Intelligence and Self-Esteem as Moderators. Social Behavior and Personality: an international journal, 42(8), 1257-1265. doi:10.2224/sbp.2014.42.8.1257

Lingiardi, V., Muzi, L., Tanzilli, A., \& Carone, N. (2018). Do therapists' subjective variables impact on psychodynamic psychotherapy outcomes? A systematic literature review. Clinical Psychology and Psychotherapy, 25(1), 85-101. doi:10.1002/cpp.2131

Linley, P. A., \& Joseph, S. (2007). Therapy Work and Therapists' Positive and Negative WellBeing. Journal of Social and Clinical Psychology, 26(3), 385-403. doi:10.1521/jscp.2007.26.3.385

Lundgren-Nilsson, Å., Jonsdottir, I. H., Ahlborg, G., \& Tennant, A. (2013). Construct validity of the psychological general well being index (PGWBI) in a sample of patients undergoing treatment for stress-related exhaustion: a rasch analysis. Health and quality of life outcomes, 11(1), 2. doi:10.1186/1477-7525-11-2 
Luyten, P., \& Fonagy, P. (2015). The Neurobiology of Mentalizing. Personality Disorders: Theory, Research, and Treatment, 6(4), 366-379. doi:10.1037/per0000117

Mallinckrodt, B. (2000). Attachment, Social Competencies, Social Support, and Interpersonal Process in Psychotherapy. Psychotherapy Research, 10(3), 239-266. doi:10.1093/ptr/10.3.239

McDowell, I. (2010). Measures of self-perceived well-being. Journal of Psychosomatic Research, 69(1), 69-79. doi:10.1016/j.jpsychores.2009.07.002

Mikulincer, M. (1995). Attachment style and the mental representation of the self. Journal of Personality and Social Psychology, 69(6), 1203-1215. doi:10.1037/0022-3514.69.6.1203

Mikulincer, M., \& Shaver, P. R. (2012). An attachment perspective on psychopathology. World Psychiatry, 11(1), 11-15. doi:10.1016/j.wpsyc.2012.01.003

Mikulincer, M., \& Shaver, P. R. (2016). Attachment in adulthood: Structure, dynamics, and change (2nd ed.). New York, NY: Guilford Press.

Morandotti, N., Brondino, N., Merelli, A., Boldrini, A., De Vidovich, G. Z., Ricciardo, S., . . Luyten, P. (2018). The Italian version of the Reflective Functioning Questionnaire: Validity data for adults and its association with severity of borderline personality disorder. PLoS One, 13(11), e0206433. doi:10.1371/journal.pone.0206433

Morel, K., \& Papouchis, N. (2015). The Role of Attachment and Reflective Functioning in Emotion Regulation. Journal of the American Psychoanalytic Association, 63(4), NP15-20. doi:10.1177/0003065115602447

Nazzaro, M. P., Boldrini, T., Tanzilli, A., Muzi, L., Giovanardi, G., \& Lingiardi, V. (2017). Does reflective functioning mediate the relationship between attachment and personality? Psychiatry Research, 256, 169-175. doi:10.1016/j.psychres.2017.06.045

Nissen-Lie, H. A., Havik, O. E., Hoglend, P. A., Monsen, J. T., \& Ronnestad, M. H. (2013). The contribution of the quality of therapists' personal lives to the development of the working alliance. Journal of Counseling Psychology, 60(4), 483-495. doi:10.1037/a0033643 
Orlinsky, D. E., Rønnestad, M. H., \& Collaborative Research Network of the Society for Psychotherapy Research. (2005). How psychotherapists develop: A study of therapeutic work and professional growth. Washington, DC: American Psychological Association.

Preacher, K. J., \& Kelley, K. (2011). Effect size measures for mediation models: Quantitative strategies for communicating indirect effects. Psychological Methods, 16(2), 93-115. doi:10.1037/a0022658

Puig, A., Yoon, E., Callueng, C., An, S., \& Lee, S. M. (2014). Burnout syndrome in psychotherapists: a comparative analysis of five nations. Psychological Services, 11(1), 8796. doi:10.1037/a0035285

Richards, K. C., Campenni, C. E., \& Muse-Burke, J. L. (2010). Self-care and well-being in mental health professionals: The mediating effects of self-awareness and mindfulness. Journal of Mental Health Counseling, 32(3), 247-264. doi:10.17744/mehc.32.3.0n31v88304423806

Sacchetti, S., Robinson, P., Bogaardt, A., Clare, A., Ouellet-Courtois, C., Luyten, P., . . Fonagy, P. (2019). Reduced mentalizing in patients with bulimia nervosa and features of borderline personality disorder: A case-control study. BMC Psychiatry, 19(1), 134. doi:10.1186/s12888-019-2112-9

Schultheis, A. M., Mayes, L. C., \& Rutherford, H. J. (2019). Associations between Emotion Regulation and Parental Reflective Functioning. Journal of Child and Family Studies, 1-11. doi:10.1007/s10826-018-01326-z

Simpson, J. A., \& Rholes, W. S. (2018). Adult attachment orientations and well-being during the transition to parenthood. Current Opinion in Psychology, 25, 47-52. doi:10.1016/j.copsyc.2018.02.019

Steel, C., Macdonald, J., \& Schroder, T. (2018). A Systematic Review of the Effect of Therapists' Internalized Models of Relationships on the Quality of the Therapeutic Relationship. Journal of Clinical Psychology, 74(1), 5-42. doi:10.1002/jclp.22484 
Steele, H., Steele, M., Croft, C., \& Fonagy, P. (1999). Infant-mother attachment at one year predicts children's understanding of mixed emotions at six years. Social Development, 8(2), 161178. doi:10.1111/1467-9507.00089

Steptoe, A., Deaton, A., \& Stone, A. A. (2015). Subjective wellbeing, health, and ageing. The Lancet, 385(9968), 640-648. doi:10.1016/S0140-6736(13)61489-0

Strauss, B. M., \& Petrowski, K. (2017). The role of the therapist's attachment in the process and outcome of psychotherapy. In How and why are some therapists better than others?: Understanding therapist effects. (pp. 117-138). Washington, DC, US: American Psychological Association.

Tabachnick, B. G., \& Fidell, L. S. (2007). Using multivariate statistics (5th ed ed.). Boston, MA: Pearson Education, Inc.

Tasca, G. A., \& Balfour, L. (2014). Attachment and eating disorders: A review of current research. International Journal of Eating Disorders, 47(7), 710-717. doi:10.1002/eat.22302

Tasca, G. A., Brugnera, A., Baldwin, D., Carlucci, S., Compare, A., Balfour, L., . . Lafontaine, M.F. (2018). Reliability and validity of the Experiences in Close Relationships Scale-12: Attachment dimensions in a clinical sample with eating disorders. International Journal of Eating Disorders, 51(1), 18-27. doi:10.1002/eat.22807

Ulloa, B. F. L., Møller, V., \& Sousa-Poza, A. (2013). How does subjective well-being evolve with age? A literature review. Journal of Population Ageing, 6(3), 227-246. doi:10.1007/s12062013-9085-0

Wei, M., Liao, K. Y.-H., Ku, T.-Y., \& Shaffer, P. A. (2011). Attachment, Self-Compassion, Empathy, and Subjective Well-Being Among College Students and Community Adults. Journal of Personality, 79(1), 191-221. doi:10.1111/j.1467-6494.2010.00677.x

Wise, E. H., Hersh, M. A., \& Gibson, C. M. (2012). Ethics, self-care and well-being for psychologists: Reenvisioning the stress-distress continuum. Professional Psychology: Research and Practice, 43(5), 487-494. doi:10.1037/a0029446 
Zelenski, J. M., Murphy, S. A., \& Jenkins, D. A. (2008). The Happy-Productive Worker Thesis Revisited. Journal of Happiness Studies, 9(4), 521-537. doi:10.1007/s10902-008-9087-4 
Table 1

Means, standard deviations and zero-order correlations for all psychological variables in the sample of Italian therapists $(N=404)$.

\begin{tabular}{lccccccc}
\hline Variable & Mean (SD) & 1. & 2. & 3. & 4. & 5. & 6. \\
\hline 1. Gender, $n$ females $(\%)$ & $320(79.2 \%)$ & - & & & & \\
2. Age & $44.01(10.30)$ & $-.20^{* *}$ & - & & & \\
3. ECR-R Anxiety & $2.50(0.87)$ & -.02 & -.04 & - & & & \\
4. ECR-R Avoidance & $2.15(0.82)$ & -.03 & .06 & $.54^{* *}$ & - & & \\
5. RFQ-C & $9.62(4.21)$ & .03 & -.07 & $-.46^{* *}$ & $-.35^{* *}$ & - & \\
6. RFQ-U & $1.46(2.14)$ & -.03 & .04 & $.35^{* *}$ & $.27^{* *}$ & $-.58^{* *}$ & - \\
7. PGWBI & $82.00(10.14)$ & .04 & $.11^{*}$ & $-.49^{* *}$ & $-.40^{* *}$ & $.45^{* *}$ & $-.33^{* *}$ \\
\hline
\end{tabular}

Note. ECR-R = Experiences in Close Relationship - Revised; RFQ-C $=$ Reflective Functioning Questionnaire - Certainty subscale; RFQ-U = Reflective Functioning Questionnaire - Uncertainty Subscale; PGWBI = Psychosocial General Well-Being Index; SD = Standard Deviation. For ease of interpretation, we presented non-transformed means and standard deviations for both ECR-R dimensions and PGWBI. In addition, RFQ-U and PGWBI Total scores were reflected and transformed, however correlations related to these scales are shown as positive for ease of interpretation. The association between gender $(0=\mathrm{M}, 1=\mathrm{F})$ and other variables was analyzed through point-biserial correlation coefficients.

$*=p \leq .05 ; * *=p \leq .01$. 


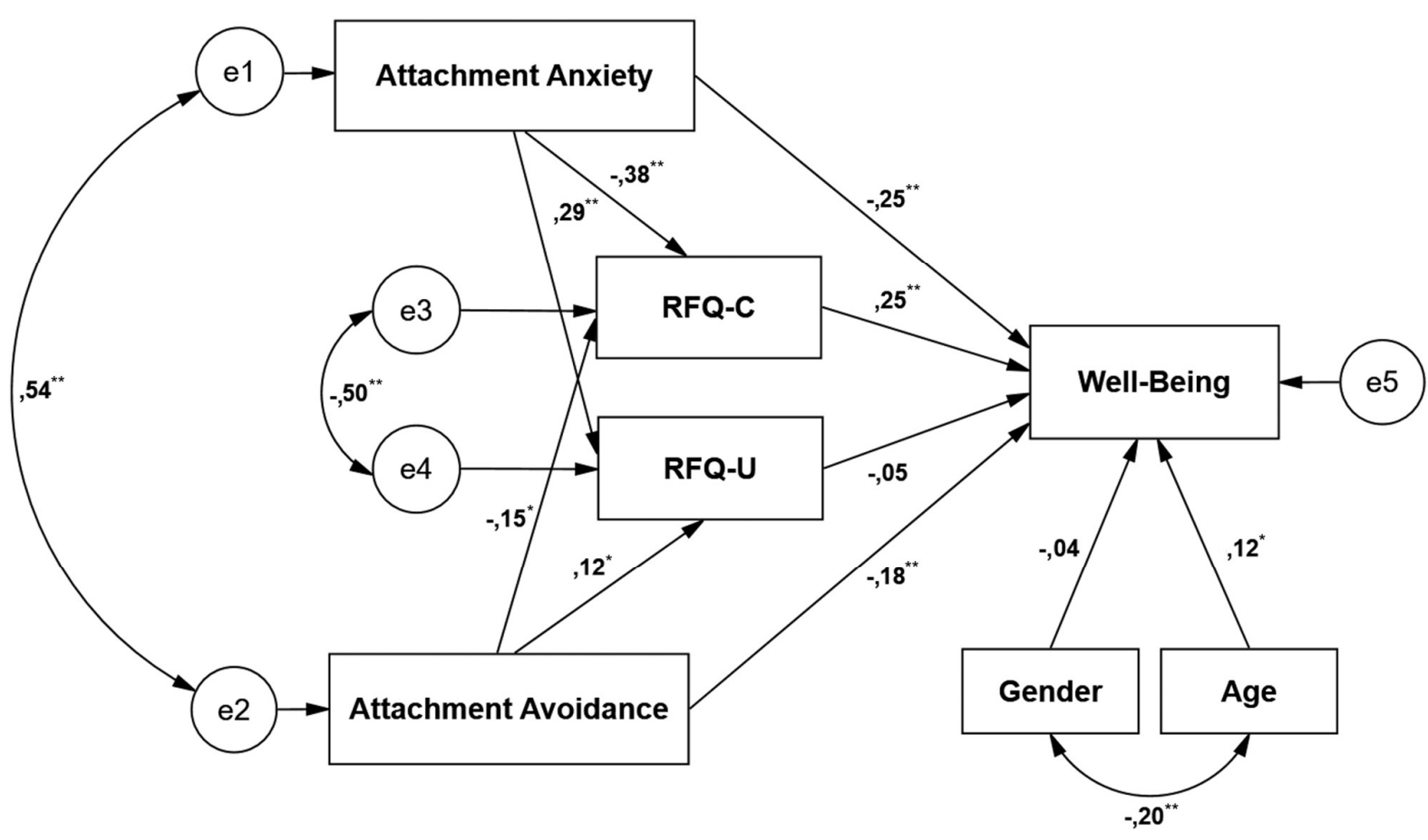

Figure 1. Path model of attachment, mentalization, and well-being among psychotherapists $(N=$ 404). Path coefficients are standardized.

Note. Attachment Anxiety = Experiences in Close Relationship - Revised, Anxiety subscale; Attachment Avoidance $=$ Experiences in Close Relationship - Revised, Avoidance subscale; RFQ$\mathrm{C}=$ Reflective Functioning Questionnaire - Certainty subscale; RFQ-U = Reflective Functioning Questionnaire - Uncertainty subscale; Well-Being = Psychosocial General Well-Being Index (PGWBI) Total score. The RFQ-U and PGWBI Total scores were reflected and transformed, however coefficients related to these scales are shown as positive for ease of interpretation. The effect of RFQ-U on PGWBI Total score was not significant.

$*=p \leq .05 ; * *=p \leq .001$. All $p$-values were still significant after the Benjamini-Hochberg correction for False Discovery Rate. 